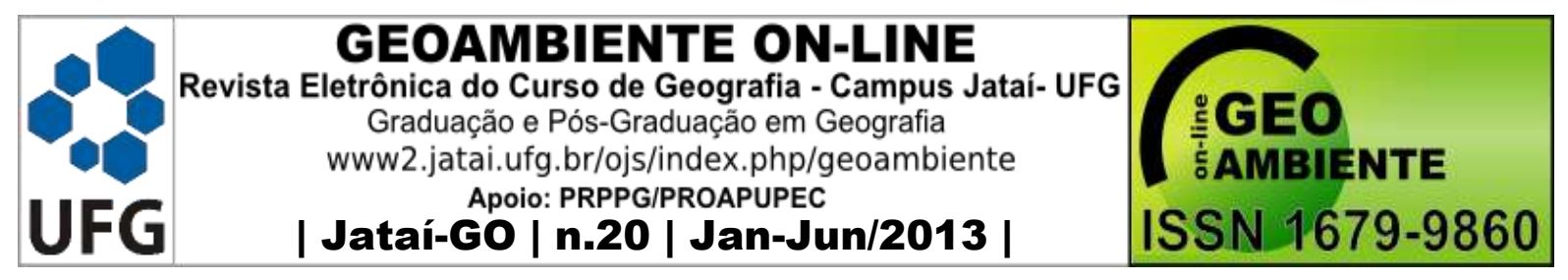

\title{
DINÂMICA CENTRO-PERIFERIA E ESTRUTURA URBANA NO \\ CONTEXTO DAS AGLOMERAÇÕES NÃO-METROPOLITANAS NO \\ INTERIOR DO ESTADO DE SÃO PAULO: O CASO DE
}

ARARAQUARA/AMÉRICO BRASILIENSE

\author{
Leandro Marcos Tessari \\ (Universidade Estadual Paulista, Campus Rio Claro, Doutorando em Geografia, \\ Imtessari@yahoo.com.br)
}

\section{Resumo}

Neste texto procura-se analisar, brevemente, a dinâmica centro-periferia e a estruturação urbana, potencializadas pelo processo de conurbação, na aglomeração urbana nãometropolitana de Araraquara/Américo Brasiliense, que estabelece novas centralidades a partir da articulação entre os fluxos intra e interurbano. Para a execução do trabalho, utilizaram-se: levantamento bibliográfico, levantamento de campo, dados estatísticos da Fundação SEADE e dos poderes públicos locais. As ações de planejamento urbano adotadas pelos poderes públicos locais encontram-se descoladas de uma ação conjunta face à aglomeração urbana. Dessa forma, compromete-se o planejamento urbano e regional pleno e integrado capaz de atuar nas novas centralidades constituídas pela lógica centro-periferia na aglomeração urbana não-metropolitana. Instrumentos de ordenação territorial devem ser adotados em conjunto e de maneira eficiente contemplando no final do processo a satisfação e a mediação plena dos agentes e indivíduos presentes nos espaços intra e interurbano em análise.

Palavras-chaves: Centro-Periferia. Estrutura Urbana. Aglomerações não-metropolitanas. Araraquara. Américo Brasiliense.

\author{
Abstract \\ CENTRE-PERIPHERY DYNAMICS AND URBAN STRUCTURE IN THE CONTEXT \\ OF URBAN-METROPOLITAN AGGLOMERATIONS NOT INTERIOR THE STATE \\ OF SÃO PAULO: THE CASE OF ARARAQUARA / AMÉRICO BRASILIENSE
}

\footnotetext{
Artigo recebido para publicação em 18 de Outubro de 2012

Artigo aprovado para publicação em 05 de Maio de 2013
} 


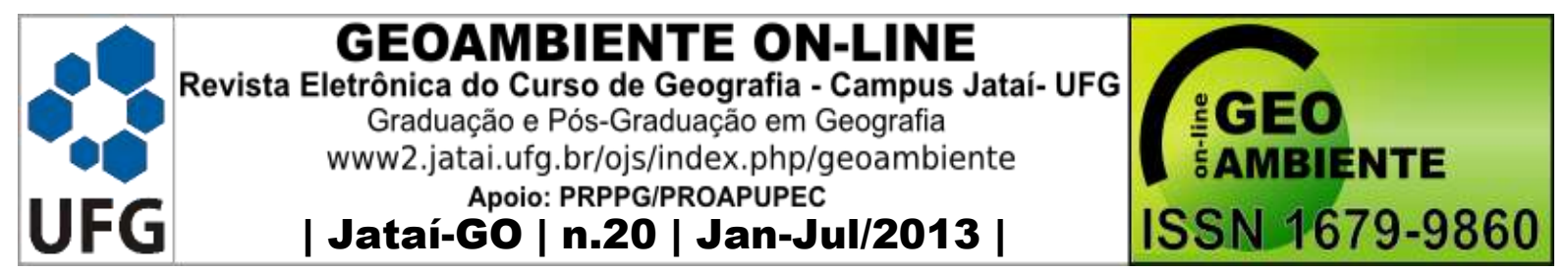

Throughout the present article, it is due to understand, briefly, the center-periphery dynamics and urban structure, enhanced by the process of conurbation, in the urban agglomeration nonmetropolitan Araraquara/Américo Brasiliense establishing new centers from the joint between the intra and interurban. For the execution of the work, it was used: bibliographical survey and survey of field, given statistics data from official sources such as SEADE Foundation and local public authorities. The actions of urban planning adopted by local authorities are unglued joint action against urban agglomeration. Thus it, compromises the urban and regional planning as fully integrated and able to act in new centers formed by the centerperiphery logic in urban agglomeration non-metropolitan. Instruments of ordination territorial should efficiently be adopted together contemplating the end of the mediation process and the full satisfaction of agents and individuals present in intra and inter spaces under consideration. Word-keys: Center-Periphery. Urban Structure. Urban Agglomeration non-metropolitan. Araraquara. Américo Brasiliense.

\section{Resumen}

\section{DINÁMICA DE PERIFERIA Y CENTRO DE ESTRUCTURA EN EL CONTEXTO} DE LA URBANOS-METROPOLITANOS AGLOMERACIONES NO EN EL ESTADO DE SÃO PAULO: EL CASO DE ARARAQUARA / AMÉRICO BRASILIENSE

En este trabajo se pretende analizar, en pocas palabras, la dinámica centro-periferia y la estructura urbana, reforzada por el proceso de conurbación, en la aglomeración urbana no metropolitana Araraquara / Américo Brasiliense establecer nuevos centros de la articulación entre la intra e interurbano. Para la ejecución de los trabajos que se utilizó: revisión bibliográfica y estudio de campo, dados los datos estadísticos procedentes de fuentes oficiales como SEADE Fundación y las autoridades públicas locales. Las acciones de planeamiento urbanístico aprobados por las autoridades locales están despegando acción conjunta contra la aglomeración urbana. Por lo tanto, se encarga de la planificación urbana y regional y se integran plenamente en condiciones de actuar en nuevos centros formados por la lógica de centro-periferia en la aglomeración urbana no metropolitana. Los instrumentos de ordenación territorial se adoptarán juntos de manera eficiente y contemplando el final del proceso de mediación y la plena satisfacción de los agentes y las personas presentes en los espacios intra e interurbano considerados. 


\begin{tabular}{|c|c|c|}
\hline & $\begin{array}{r}\text { GEOAN } \\
\text { Revista Eletrônica do } \\
\text { Graduacăóo } \\
\text { www2.jatai. } 4 \\
\text { | Jataí-Go }\end{array}$ & $1679-9860$ \\
\hline
\end{tabular}

Palabras-claves: Centro-Periferia. Estructura Urbana. Aglomeración urbana no metropolitana. Araraquara. Américo Brasiliense.

\section{1 - Introdução}

O crescimento acelerado da população urbana, principalmente durante as últimas décadas em cidades médias, tem sido acompanhado por um grande aumento na demanda de áreas urbanas voltadas ao uso residencial, comercial ou industrial. Essa procura proporcionou um desenvolvimento e uma expansão dos espaços urbanos, principalmente nas áreas periféricas ou franja urbano-rural dessas cidades. Tais processos têm contribuído para a fragmentação do tecido urbano e influenciado, diretamente, nas condições de vida da população.

As aglomerações urbanas, formadas no contexto das cidades médias paulistas, constituem um 'novo território regional' que a partir das duas últimas décadas do século XX, têm ampliado seus papéis econômicos, seja pela desconcentração territorial das unidades de produção industrial da metrópole para o interior, seja pela centralização das atividades agroindustriais a partir das culturas tecnificadas agroexportadoras, além da multiplicação das atividades comerciais e de serviços nelas sediadas. Essas dinâmicas redefinem e aprofundam a divisão territorial do trabalho alterando as dinâmicas socioespaciais presentes nessas cidades, bem como no entorno regional, consolidando e diversificando a formação das aglomerações urbanas não-metropolitanas, com estruturas urbanas mais complexas. Nesse sentido, altera-se a lógica centro-periferia não somente no aspecto intraurbano como também no aspecto interurbano com novas formas e conteúdos.

A relação centro-periferia que se estabelece em uma aglomeração urbana nãometropolitana constitui um elemento decisivo na compreensão de novas dinâmicas espaciais que se estruturam no aspecto regional provocando mudanças no tecido da aglomeração como um todo. Portanto, analisando o tecido urbano da aglomeração não-metropolitana redefinemse novas centralidades específicas de cada tecido urbano, apresentando-se uma interdependência entre as dinâmicas que envolvem a estrutura intraurbana das cidades e também do espaço interurbano da aglomeração, como a espacialização dos equipamentos de comércio e de serviços, moradias, infraestrutura e vias de circulação.

Para se pensar a dinâmica das aglomerações urbanas, consolidadas a partir das cidades médias, em especial as não-metropolitanas, nos dias de hoje, se faz necessário entender os 


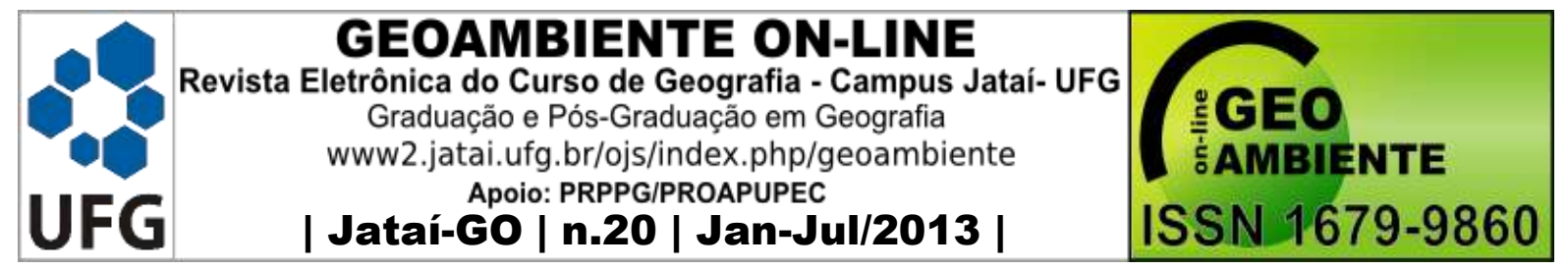

processos que envolvem a produção e estruturação desse espaço, segundo análises sociais e espaciais. Os processos sociais representam a forma, o movimento e o conteúdo sobre o espaço, viabilizando um conjunto de forças que atuam ao longo do tempo e que permitem localizações, realizações e permanência das atividades e populações sobre o espaço intra e interurbano. Já os processos espaciais representam a organização espacial desse espaço como sendo um conjunto contraditório e complementar, ou seja, fragmentado e articulado.

Alguns desses elementos contribuem para promover uma inadequada ocupação e uso do solo, influenciando também no bem-estar social da população. Assim, o papel do planejamento se apresenta como uma ferramenta que auxilia em uma estruturação urbana adequada, para os diversos segmentos da sociedade.

Sem a pretensão de promover um levantamento do Estado da Arte dos temas abordados, o objetivo deste trabalho é analisar, brevemente, as dinâmicas centro-periferia na estruturação e ampliação das relações entre os espaços urbanos que formam a aglomeração urbana não-metropolitana de Araraquara/Américo Brasiliense com o estabelecimento de novas centralidades, além de compreender as ações dos poderes públicos locais na articulação dos processos de ordenamento territorial entre os fluxos intra e interurbano da conurbação.

Para a consecução desses objetivos foi necessário o levantamento bibliográfico sobre os temas propostos, dentre eles: dinâmica centro-periferia, expansão urbana e conurbação, em periódicos, livros, anais de congressos e outros; o levantamento de campo (entrevistas e levantamento cartográfico); coleta de dados estatísticos em fontes oficiais de dados como a Fundação SEADE (Sistema Estadual de Análise de Dados), além de informações fornecidas pelas prefeituras das cidades acima citadas.

\section{2 - Dinâmica Centro-Periferia e Estrutura Urbana}

As dinâmicas socioespaciais presentes no espaço das aglomerações urbanas favorecem a produção de um crescimento urbano disperso e periférico resultando, em alguns casos, em um sistema urbano conurbado que extrapola os limites territoriais administrativos e redefine a escala urbano-regional. Essas interações provenientes de ações econômicas e sociais expressam a dinâmica do sistema de acumulação determinando a forma de produção e a modificação do espaço construído.

Assim, a dinâmica da expansão urbana pode ser compreendida a partir de dois prismas: o da escala da cidade e o da escala regional. O primeiro, relativo à escala da cidade, é 


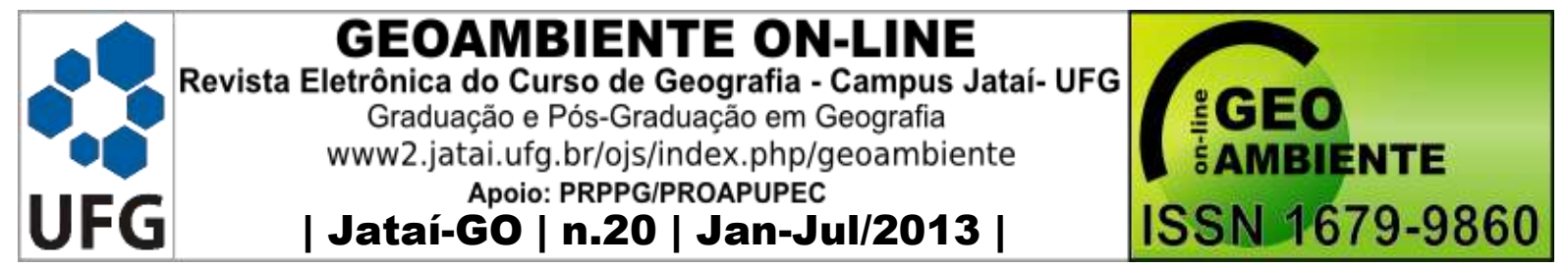

utilizado para assinalar a criação de novos territórios urbanizados, aos quais correspondem processos de infraestruturação e de reparcelamento de propriedades originalmente não urbanas, e que se traduzem no progressivo crescimento da dimensão das cidades. Já o segundo prisma diz respeito à escala regional e a expansão urbana diz respeito ao fenômeno de crescimento urbano dos aglomerados, ou seja, do alargamento dos perímetros urbanos e ocupação do espaço com o povoamento que, sendo aglomerado em torno de vilas e cidades, pode ser traduzido pelo fenômeno da urbanização do território ${ }^{1}$.

O sistema de transporte, diretamente ligado ao deslocamento de pessoas e mercadorias, atrai a ocupação urbana nos pontos de grande acessibilidade ou de possíveis acessibilidades, o que altera o valor de uso da terra e passa a gerar uma nova oferta de demandas locacionais que são ocupadas por uma parcela da população e atividades econômicas que foram produzidas a partir do centro da cidade em expansão. Além do sistema local de transporte e das ações resultantes dele, o enfoque no deslocamento regional também se apresenta como um motor que facilita a circulação e, consequentemente, o fenômeno da expansão urbana, que pode favorecer a posteriori o processo de conurbação.

Nesse contexto, o deslocamento regional surge como um subproduto do sistema ... interurbano, representado por uma parte desse sistema que a cidade recebe não só
antes da demanda, mas também gratuitamente. [...] À medida que a cidade cresce,
ela se apropria e absorve os trechos urbanos das vias regionais, como nos casos das
rodovias antigas que, com o tempo, se transformaram em vias urbanas. É a
mudança de função da via (que passa a ser tráfego intraurbano) e, não sua
localização (dentro ou fora da cidade), que transforma uma via regional em urbana.
(VILLAÇA, 2001, p.82)

Contrariamente, grande parte dos trabalhos acadêmicos que tratam do tema da expansão urbana constatam que o processo é tido como algo natural e espontâneo, que decorre da ampliação de dados quantitativos da população de uma ou de outra cidade, além de resultar

\footnotetext{
${ }^{1}$ A respeito da utilização da categoria território para o entendimento da produção do tecido urbano, concorda-se com as ideias apresentadas por Spósito (2004) de que "a utilização do termo território ou territorial aporta-se à dimensão material da cidade, à base física sobre a qual se assenta a cidade, ou seja, o espaço topográfico ocupado por ela, o que poderia ser, numa primeira vista designado pelo conceito de sítio urbano. Entretanto, o território urbano é mais que o sítio urbano, porque outras três dimensões [jurídica, infraestrutural e as formas grifo nosso] estão [...] contidas na acepção do conceito para se entender a expansão urbana". (SPÓSITO, 2004, p.73-74).
} 


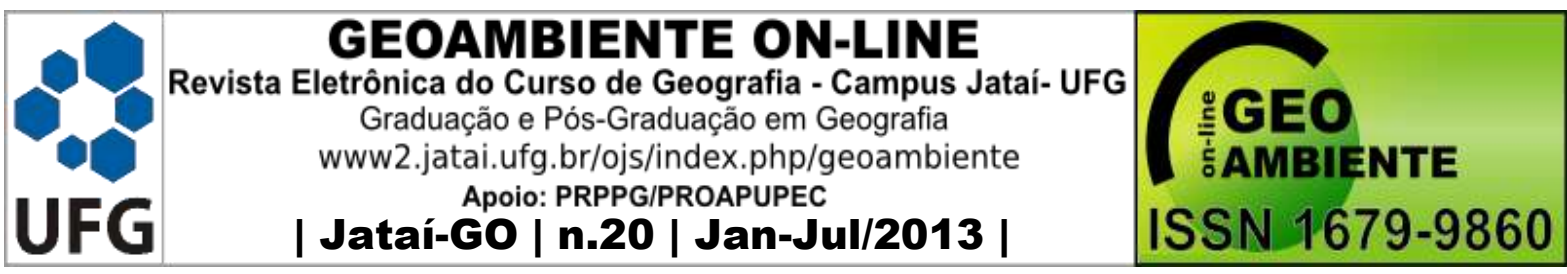

em uma configuração espacial fragmentada. Pensar a expansão urbana no sentido literal do termo não corresponde somente à análise desses dados quantitativos de pessoas, mas entender, em termos espaciais da cidade como também da aglomeração urbana nãometropolitana, que essa expansão se concretiza segundo diferentes lógicas superpostas em um mesmo espaço e amplia distâncias entre a área central e as novas áreas urbanizadas, redefinindo a lógica centro-periferia, bem como a estruturação urbana.

Para Spósito (2004), essa redefinição centro-periferia, sintetiza-se, entre outros aspectos,

pela diminuição do número de cidades médias e grandes estruturadas em torno de um centro único, onde se reunia a maior parte das atividades comerciais e de serviços públicos e privados, e aparecimento de novos equipamentos e formas de organização do consumo (shopping centers, centros de negócios, parques para lazer etc.), ampliando a tendência de estruturações urbanas com múltiplas áreas centrais. (SPÓSITO, 2004, p. 125-126)

A respeito dessa temática Spósito (2001) complementa que a situação dessa urbanização

\begin{abstract}
é um processo que se reconstrói, também, com espacialidades que se redesenha a partir da fragmentação do tecido urbano e da intensificação da circulação de pessoas, mercadorias, informações, ideias e símbolos. Já que hoje, não temos mais, apenas, um processo de urbanização pelo aumento do número e tamanho das cidades e dos papéis que desempenham na divisão social do trabalho. [...] Pois, o meio técnico-científico coloca cada vez mais a cidade além da cidade, redefinindo a dialética cidade-urbano. Essa redefinição encerra uma outra: a relação cidade urbanidade. (SPÓSITO, 2001, p. 85)
\end{abstract}

A partir dessa análise, a cidade representa uma imensa concentração de agentes que exercem diferentes atividades nesse espaço. Sendo assim, a expansão urbana tende a privilegiar determinadas localizações em medida tanto mais quanto mais escassos forem os serviços em relação à demanda. Em grande parte das cidades, a rápida expansão do seu número de habitantes resulta em uma escassez de solo urbano, bem como de equipamentos urbanos, resultando na valorização das poucas áreas bem servidas de infraestrutura. A atuação do mercado imobiliário confere a essas áreas bem servidas de infraestrutura urbana um privilégio das camadas de alta renda que possuem reais condições de consumir esse espaço, enquanto a população de baixa renda fica destinada às zonas mal servidas e que, por isso, são mais baratas (SINGER, 1982). Tal questão evidencia um ponto relevante, no que diz respeito ao processo de expansão urbana, ou seja, conclui-se que o arranjo espacial dos bairros, bem como da população no espaço urbano, resulta de um 


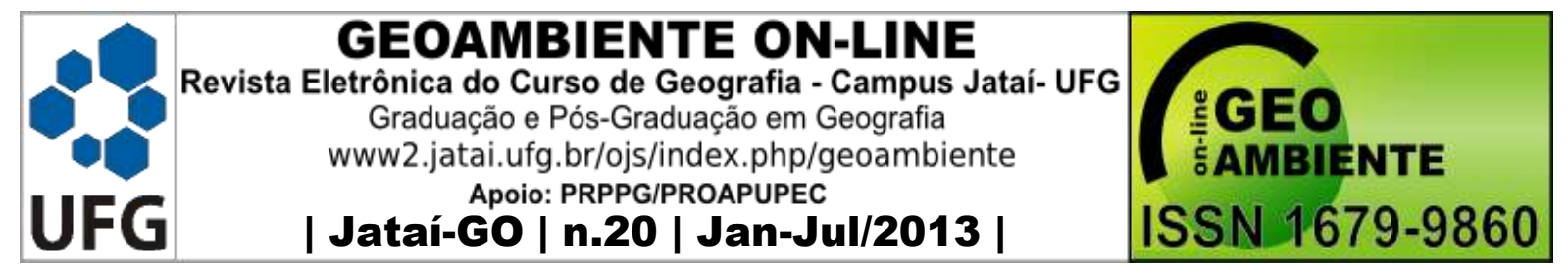

processo dialético, em que a segregação de uns provoca, ao mesmo tempo e pelo mesmo processo, a segregação de outros, sendo um processo necessário à dominação social, econômica e política por meio do espaço. (VILLAÇA, 2001,p.148)

As cidades brasileiras possuem, geralmente, um centro principal onde se localizam quase todos os serviços principais, desde órgãos administrativos (principalmente de caráter público), a igreja matriz, os tribunais, o distrito financeiro, o comércio atacadista e varejista, cinemas, teatros etc. Com o crescimento da cidade, centros secundários de serviços vão surgindo em bairros, que originam novos pontos de valorização do espaço urbano. Assim, esse crescimento urbano implica necessariamente uma nova configuração do uso das áreas já ocupadas que esbarra, na maioria das vezes, em zonas residenciais de padrão elevado. Entretanto, devido ao dinamismo do próprio espaço urbano, bem como dos agentes que moldam e articulam esse espaço, percebe-se um deslocamento populacional para novas áreas residenciais, providencialmente criadas pelos promotores imobiliários (SINGER, 1982).

Como complementa Lopes Jr. et al. (2009),

as localizações que são disputadas no espaço intraurbano, seja em sua produção como consumo, são as responsáveis pela segregação socioespaciais de modo a explicitar as novas centralidades na perspectiva da relação centro-periferia. (LOPES Jr. et al., 2009, p.358)

Nesse ponto, o crescimento do espaço urbano para as áreas periféricas resulta de uma necessidade "imposta" pelo próprio crescimento da cidade, em especial de sua zona comercial. Entretanto o que se tem notado em grande parte das cidades brasileiras, referente ao seu crescimento espacial, é fruto de interesses articulados pela acumulação de capital. Vale ressaltar que a partir desses fenômenos apresentados anteriormente, pode-se entender que o espaço urbano, resultado dessa desagregação habitacional, comercial e infraestrutural, se porta de maneira fragmentada e segregada socioeconomicamente, resultando no crescimento urbano disperso e periférico, porém articulado pelas vias de circulação intra e interurbana.

A análise da relação centro-periferia que se estabelece em uma aglomeração urbana não-metropolitana representa um elemento decisivo na compreensão de novas dinâmicas espaciais que se estruturam no aspecto regional provocando mudanças no tecido da aglomeração como um todo. Assim, analisando o tecido urbano da aglomeração não- 


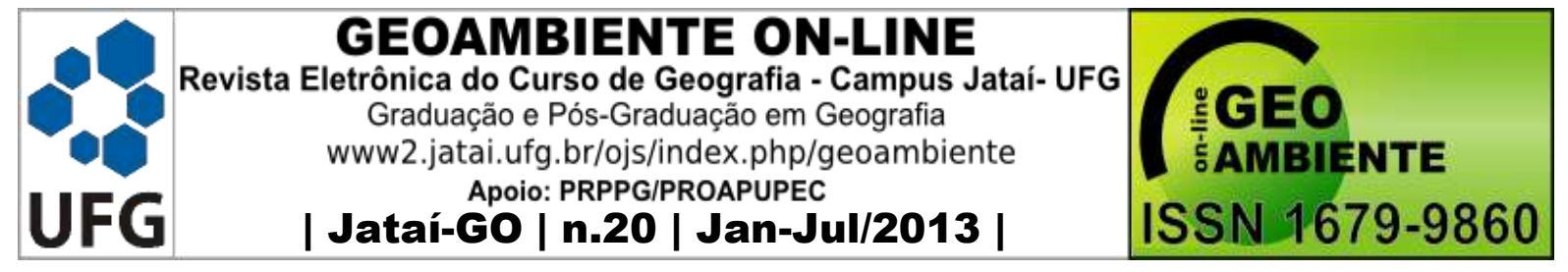

metropolitana redefinem-se novas centralidades específicas de cada tecido urbano, observando-se uma interdependência entre as dinâmicas que envolvem a estrutura intraurbana das cidades e também do espaço interurbano da aglomeração, como a espacialização dos equipamentos de comércio e de serviços, moradias, infraestrutura e vias de circulação. Assim, ao analisar uma aglomeração urbana não-metropolitana verifica-se que esse mesmo processo que altera a estrutura espacial do espaço intraurbano, materializa-se no espaço interurbano, redefinindo e aprofundando a complexa divisão territorial do trabalho, bem como os diversos usos do solo urbano no contexto da aglomeração.

Na literatura, os trabalhos já desenvolvidos referentes à dinâmica centro-periferia, bem como análises sobre as centralidades associam os temas a uma análise intrametropolitana, como é o caso de São Paulo, e até mesmo ao aspecto particular de uma cidade. Os apontamentos levantados no transcorrer do texto não visam dar conta do esgotamento dos assuntos, devido à sua complexidade e dificuldade conclusiva. Com a interiorização do desenvolvimento e o crescimento da população em cidades médias paulista, consolidando aglomerações urbanas não-metropolitanas, especialmente conurbada, como no caso de Araraquara/Américo Brasiliense e outras, nota-se que não existem trabalhos referentes à temática estabelecida voltados para entender essa nova dinâmica espacial.

\section{3 - Caracterização da Área de Estudo}

\subsection{Localização}

A aglomeração urbana não-metropolitana de Araraquara/Américo Brasiliense encontra-se constituída pelo processo de conurbação entre as cidades de Araraquara e Américo Brasiliense, área de estudo da presente proposta, que se localizam, respectivamente, a 269 quilômetros e 280 quilômetros da capital, integrando-se a Região Central do Estado de São Paulo, conforme a figura 01.

As cidades de Araraquara e Américo Brasiliense são servidas por uma densa malha rodoviária, em especial a rodovia Washington Luís (SP-310), um dos principais eixos de desenvolvimento do estado, o que facilita as trocas e os fluxos de bens, pessoas e serviços. Ainda, na cidade de Araraquara, encontra-se instalado um aeroporto regional, com linhas aéreas diárias. 


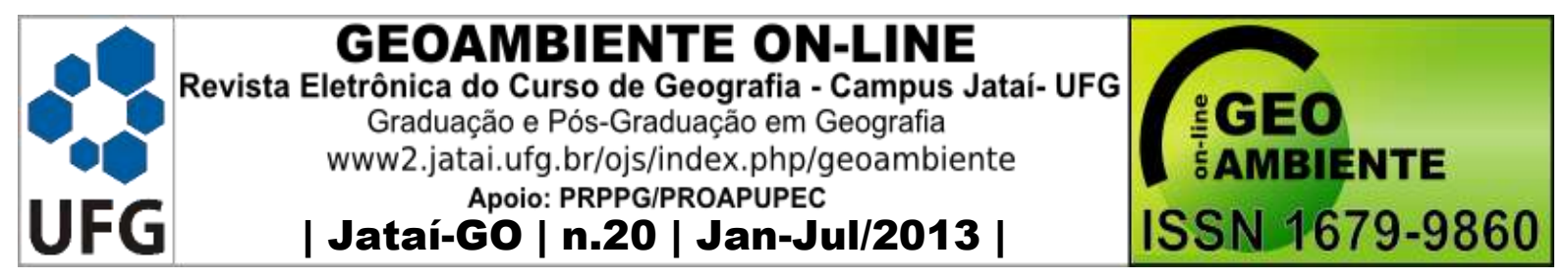

Fig. 01 - Localização de Araraquara e Américo Brasiliense no estado de São Paulo

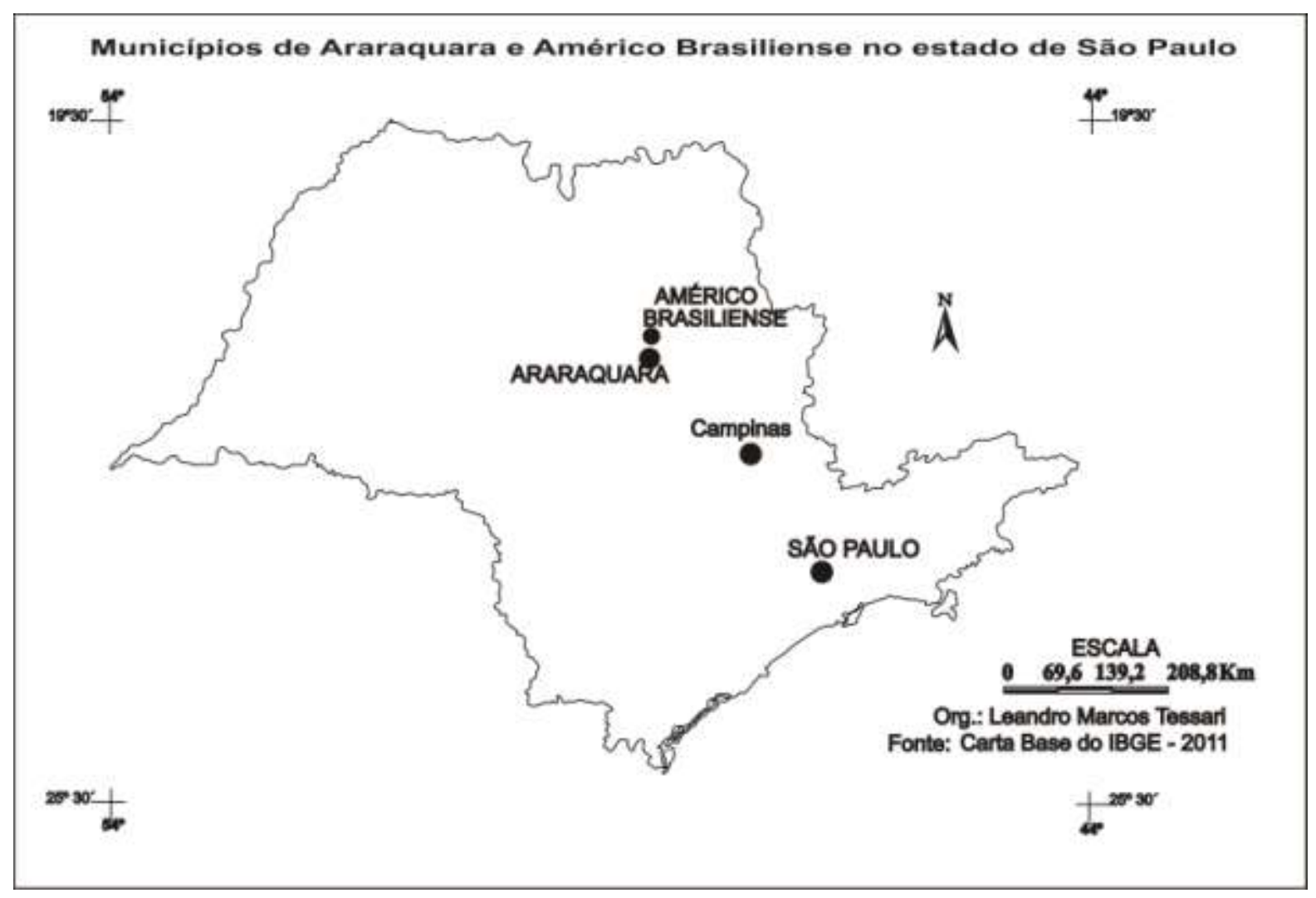

\subsection{Caracterização Socioeconômica}

A caracterização socioeconômica dos municípios em análise teve como base os dados da Fundação SEADE (Sistema Estadual de Análise de Dados), pesquisas de campo, além de informações fornecidas pelas Prefeituras. Segundo dados da Fundação Sistema Estadual de Análise de Dados - SEADE (2011), a população total do município de Araraquara é de 211.247 habitantes, dos quais 97,2\% se encontram instalados na área urbana. Já o município de Américo Brasiliense possui uma população total de 35.115 habitantes, dos quais 99,2\% se encontram instalados na área urbana. A distribuição da população de ambos por faixas etárias se aproxima quando comparados com o estado de São Paulo, conforme a tabela 01, indicando um predomínio de população jovem-adulta, período de vida voltado para a qualificação profissional e para o exercício do trabalho, indicando, assim, a necessidade de investimentos para ampliação do número de postos de trabalho.

A aglomeração urbana, formada pelas cidades de Araraquara e Américo Brasiliense, desempenha um papel primordial no cenário regional, devido à sua diversificada gama de serviços oferecidos que compreende todos os setores da economia e firma-se constantemente 


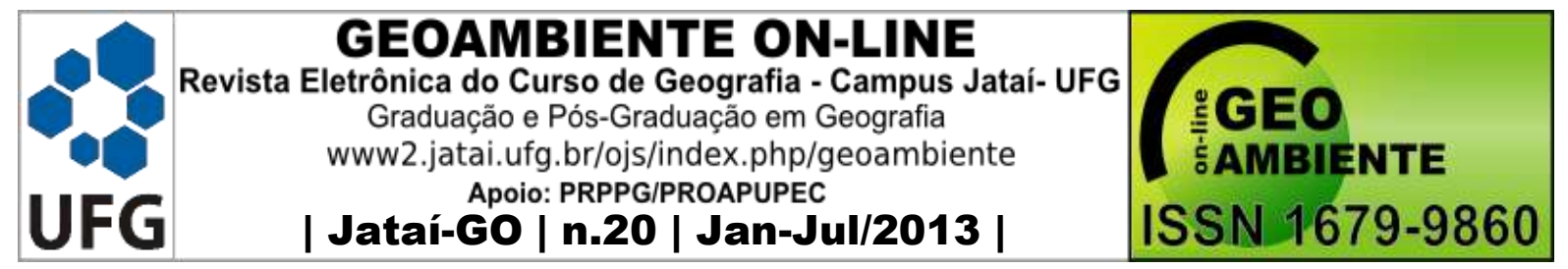

como um centro regional voltado em especial para o comércio, garantindo o atendimento de sua população, bem como da população dos municípios vizinhos, conforme a tabela 02 .

Tabela 01 - Distribuição da População por Faixas Etárias (em \%) em Araraquara, Américo Brasiliense e no Estado de São Paulo (2011)

\begin{tabular}{l|c|c|c}
\hline \multicolumn{1}{c|}{ Faixas Etárias } & Araraquara & $\begin{array}{c}\text { Américo } \\
\text { Brasiliense }\end{array}$ & $\begin{array}{c}\text { Estado de São } \\
\text { Paulo }\end{array}$ \\
\hline População com idade inferior a 15 anos & 18,3 & 23,8 & 21,5 \\
\hline População com idade entre 16 e 59 anos & 68,7 & 68,3 & 67,0 \\
\hline População acima de 60 anos & 13,9 & 7,9 & 11,5 \\
\hline
\end{tabular}

Fonte: Fundação Seade, 2011.

Tabela 02 - Valor Adicionado por Setores da Economia de Araraquara e Américo Brasiliense (em \%) para os anos de 2000 - 2009

\begin{tabular}{c|c|c|c|c}
\cline { 2 - 5 } & \multicolumn{2}{c|}{ Araraquara } & \multicolumn{2}{c}{ Américo Brasiliense } \\
\hline Anos & $\mathbf{2 0 0 0}$ & $\mathbf{2 0 0 9}$ & $\mathbf{2 0 0 0}$ & $\mathbf{2 0 0 9}$ \\
\hline Setor Primário & 1,8 & 1,8 & 4,6 & 1,2 \\
\hline Setor Secundário & 25,7 & 24,7 & 36,1 & 49,8 \\
\hline Setor Terciário & 72,5 & 73,5 & 59,3 & 49 \\
\hline
\end{tabular}

Fonte: Fundação Seade, 2011.

$\mathrm{Na}$ aglomeração em análise nota-se que, no período analisado, tanto a agricultura quanto a indústria sofreram um crescimento, diferentemente do setor de comércio e serviços. Vale salientar que nesses municípios predominam as culturas tecnificadas de cana-de-açúcar e laranja, ligadas exclusivamente ao setor agroindustrial.

\subsection{Vias de Circulação na Estruturação da Dinâmica Centro-Periferia da Aglomeração Urbana Não-Metropolitana}

O processo de urbanização em Araraquara resultou na produção do tecido urbano fragmentado e disperso. Esse fato produziu reflexos no espaço interurbano do município vizinho, Américo Brasiliense. Entende-se, dessa forma, que o sistema urbano-regional presente nos dois municípios, se apresenta como claros resultados de políticas urbanas implementadas visando a atender interesses específicos a partir da mobilidade coletiva.

O fenômeno da conurbação, presente entre os tecidos urbanos, é compreendido como um sistema funcional urbano, com alterações na dinâmica de estruturação urbana a partir de novas lógicas centro-periferia que se manifestam, cujas relações produtivas, sociais e culturais 


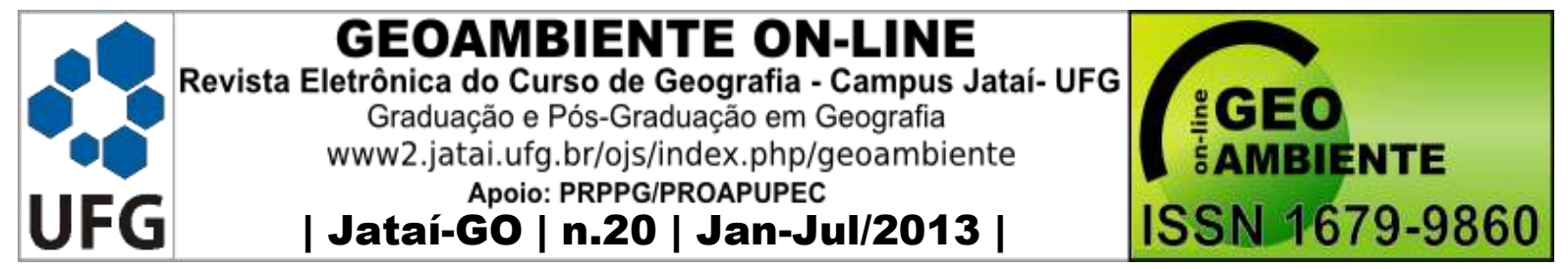

não são apenas resultados de um espaço urbano que se transborda sobre outro, mas de uma contínua rede de infraestrutura de transportes e comunicação (SOARES, 2006).

Nesse contexto, Soares (2006) considera que a proposta para um "sistema funcional urbano"

[...] constitui um âmbito de vida, de mobilidade pendular cotidiana e de mobilidade residencial daqueles que vivem em um território urbanizado, conurbado [grifo nosso], que se estende por até dezenas de quilômetros [...] correspondem a mercados de trabalho e de serviços geograficamente distintos, mas que ao serem formados por diferentes centros articulados por sistemas de transporte e comunicações rápidos, equivalem à escala do município em históricos períodos anteriores. (SOARES, 2006, p.351)

As vias regionais de circulação são importantes, pois são marcos estratégicos para a consolidação e estruturação da urbanização, dos vetores de crescimento urbano, bem como para a compreensão centro-periferia no contexto da aglomeração urbana ${ }^{2}$. Tem-se em vista que os deslocamentos produzidos no interior de cada espaço são reflexos de uma integração regional pretérita, materializada fundamentalmente pelas vias regionais de circulação, o que possibilita a interação de funções urbanas, bem como ações complementares de integração econômica, social, serviços públicos de interesse regional etc. A localização e o movimento, ou seja, os fluxos, materiais e imateriais, pressupõem uma prévia articulação entre ambos saindo do campo teórico e se materializando empiricamente através dos deslocamentos de pessoas, veículos, mercadorias, serviços, conhecimento, tecnologia etc.

A esse respeito a tabela 03 demonstra os deslocamentos de passageiros na linha suburbana entre Araraquara e Américo Brasiliense providos pela empresa prestadora do serviço. Muitos dos passageiros, quando indagados a respeito do porquê do deslocamento de Américo Brasiliense para Araraquara, apontam vários motivos, entre eles: trabalho, estudo (ensino superior), serviços sociais (Agência da Previdência Social - INSS), compras no comércio central e nos finais de semana em shopping centers. Em Araraquara há dois desses centros de compras somando um total de 86 estabelecimentos comerciais, incluindo cinemas e supermercados, um deles localizado na região central da cidade e outro na franja urbano-rural da cidade, próximo à rodovia SP-310. Já no trajeto contrário, a ida a Américo Brasiliense,

\footnotetext{
${ }^{2}$ Nos aspectos tratados da conurbação entre Araraquara e Américo Brasiliense, o conceito de aglomeração urbana aplica-se a uma área não-metropolitana. $\mathrm{O}$ aspecto legal da aglomeração urbana deve ser realizado por meio de lei complementar fundamentada em estudos técnicos que comprovem a existência dos requisitos exigidos e da realização de audiência junto aos municípios interessados.
} 


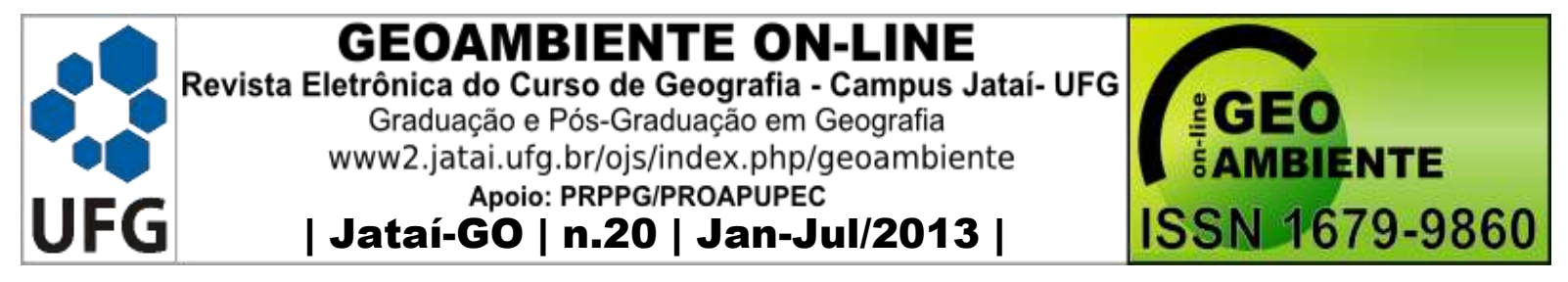

Esses deslocamentos e a circulação, descritos anteriormente, são de fato elementos inquestionáveis dessa integração do conjunto das cidades, em face da consolidação da aglomeração não-metropolitana, não apenas no campo econômico, como atração de indústrias, parques empresarias etc., mas também urbano, educacional, jurídico, entre outros.

Nesse sentido, verifica-se no interior dessa aglomeração urbana uma lógica centroperiferia. Ao contrário da posição subalterna (tradicional) da periferia, ou do próprio termo periferia, tem-se nesse espaço interurbano a formação de um crescimento polinucleado, cuja dinâmica de estruturação ocorre através da vias de circulação regional, facilitando a mobilidade demográfica e o acesso às novas centralidades, resultando na redefinição das hierarquias no conjunto da rede urbana.

\section{4 - Considerações Finais}

A dinâmica centro-periferia deve ser compreendida no contexto da aglomeração urbana não-metropolitana de Araraquara/Américo Brasiliense não apenas como sendo formada por seus elementos materiais, mas como uma forma de organização inter-intraurbana dessa aglomeração, isto é, a forma como produz, o uso que dá aos materiais, o grau de interrelação das suas atividades, de sua contribuição para a potencialização de novas dinâmicas espaciais que se estruturam no aspecto regional provocando mudanças no tecido da aglomeração como um todo.

Analisando o tecido urbano da aglomeração não-metropolitana de Araraquara/Américo Brasiliense verificam-se novas centralidades constituídas de cada tecido urbano, apresentando uma interdependência entre as dinâmicas que envolvem a estrutura intraurbana das cidades, bem como do espaço interurbano da aglomeração, com a espacialização dos equipamentos de comércio e de serviços, moradias, infraestrutura e vias de circulação. Assim, considera-se que esse mesmo processo, que altera a estrutura espacial do espaço intraurbano, se materializa no espaço interurbano, redefinindo e aprofundando a complexa divisão territorial do trabalho, bem como os diversos usos do solo urbano em Araraquara e Américo Brasiliense.

As ações de planejamento urbano adotadas pelas cidades de Araraquara e Américo Brasiliense encontram-se descoladas de uma ação conjunta dos poderes públicos locais, tendo em vista o fenômeno da aglomeração urbana, bem como a conurbação existente. Isso compromete um planejamento urbano e regional pleno e integrado capaz de atuar nas novas 


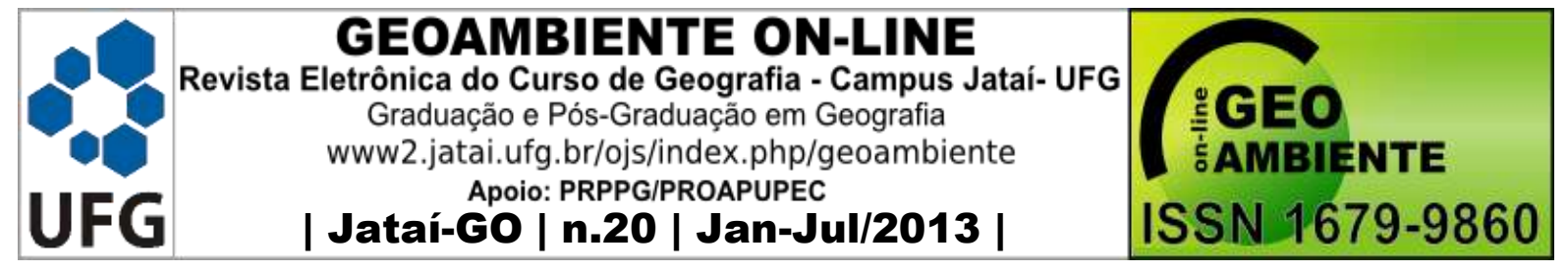

centralidades que foram sendo constituídas pela lógica centro-periferia, produzindo segregações socioespaciais na consolidação da aglomeração urbana não-metropolitana. Instrumentos de ordenação territorial devem ser adotados em conjunto e de maneira eficiente para que contemplem no final do processo a satisfação e a mediação plena dos agentes e indivíduos que se fazem presentes nos espaços intra e interurbano em análise.

Pensar as ações do planejamento urbano para as áreas de aglomeração urbana, em especial as não-metropolitanas, no que diz respeito à estruturação de novas relações de centroperiferia é pensar a teoria e a prática, fundamentadas na coletividade regional, visando nortear ações dos agentes e atores dos espaços urbanos envolvidos. Esse foco deve visar, ao final, à efetivação de planejamento urbano/regional pleno, resultando numa mudança social positiva e na construção de aglomerações urbanas verdadeiramente integradas, dinâmicas e modernas.

\section{5 - Bibliografia}

BATTEN, D. Network cities: creative urban agglomerations for the 21st Century. Urban Studies, Vol. 32(2), 313-327. 1995.

BENNER, N. Decoding the newest "Metropolitan Regionalism" in the USA: a critical overwiel. Cities, Vol. 19(1), 3-21, 2002.

CANDIOTTO, L. Z. P.; CORRÊA, W. K. Ruralidades, Urbanidades e a Tecnicização do Rural no contexto do debate Cidade-Campo. Campo-Território: Revista de Geografia Agrária, Uberlândia, v.3, n. 5, 214-242, fev. 2008.

CORRÊA, R. L. Estudos sobre a rede urbana. Bertrand Brasil, Rio de Janeiro, 2006.

DAVIDOVICH, F.; LIMA, O. M. B. Contribuição ao estudo das aglomerações urbanas no Brasil. Revista Brasileira de Geografia, IBGE, Rio de Janeiro: IBGE, ANO 37 número 1, p. 50-84, jan/mar 1975.

DEMATTEIS, G. Suburbanización y periurbanización. Ciudades anglosajonas y ciudades latinas. La ciudad dispersa: suburbanización y nuevas periferias, Centre de Cultura Contemporánea, Barcelona, 1998.

DÉZERT, B. Metropolisation et exurbanisation. Bulletin de l'Association des Géographes Français, Paris, n.2, 133-138, 1991.

GEDDES, P. Cidades em evolução. Tradução de Maria José Ferreira de Castilho. Papirus, Campinas, 1994. 


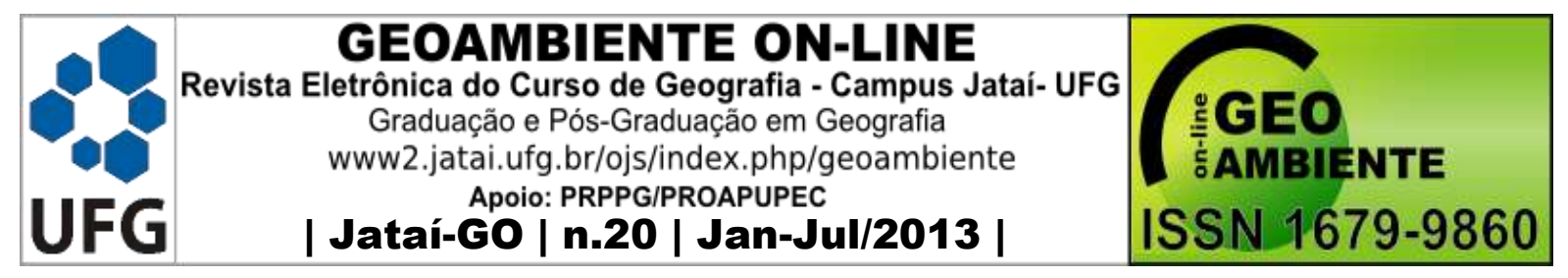

GOTTDIENER, M. A produção social do espaço urbano. Tradução de Geraldo Gerson de Souza. Editora da Universidade de São Paulo, São Paulo,1993.

HARVEY, D. A condição pós-moderna, Loyola, São Paulo,1992.

IPEA, NESUR/IE - Unicamp, IBGE. Caracterização e Tendências da Rede Urbana Brasileira. IPEA, Brasília: IPEA, 1999.

KLINK, J. A cidade-região: regionalismo e reestruturação no grande ABC Paulista, : DP \& A Editora, Rio de Janeiro, 2001.

LOPES JR, W. M.; SANTOS, R. B. dos. Novas centralidades na perspectiva da relação centro-periferia. Revista Sociedade \& Natureza, Uberlândia, v.21(03), 351-359, 2009.

MARQUES, E. C.; BICHIR, R. M. Investimentos públicos, infraestrutura urbana e produção da periferia de São Paulo. Espaço \& Debates, São Paulo, n.42, 09-31, 2001.

MATOS, R. Aglomerações Urbanas, Redes de Cidades e Desconcentração Demográfica no Brasil. Artigo obtido no site: http://www.abep.nepo.unicamp.br/docs/anais/pdf/2000/Todos/migt4_3.pdf $\quad$ NEPO _ UNICAMP, Campinas, 01 - 21, 2000.

MAUTNER, Y. A periferia como fronteira de expansão do capital, In: DEÁK, C.; SCHIFFER, S. R. (Org.). O processo de urbanização no Brasil, EDUSP, São Paulo, 1999.

MOURA, R.; BRANCO, M. L. G. C.; FIRKOWSKI, O. L. de F. Movimento pendular e perspectivas de pesquisas em aglomerados urbanos. São Paulo em Perspectiva, v.19(4), 121$133,2005$.

REOLON, C. A.; MIYAZAKI, V. K. Conflitos entre processo de aglomeração urbana e de instituições de unidades regionais em cidades não-metropolitanas no Brasil. XII Encontro de Geógrafos da América Latina, Montevideo, 2009.

RIBEIRO, L. C. de Q.; LAGO, L. C. Reestruturação nas Grandes Cidades Brasileiras: o modelo centro/periferia em questão. Artigo obtido no site: http://www.observatoriodasmetropoles.ufrj.br/download/reestruturacao_cidades.pdf IPPUR UFRJ, Rio de Janeiro, 01 - 19, 1994.

SANTOS, M. A Urbanização Brasileira, 5. ed., Edusp, São Paulo, 2005.

A Natureza do Espaço: Técnica e Tempo, Razão e Emoção, 4. ed., 2. reimpr., Edusp, São Paulo, 2006.

SERRA, G. G. Rodovias, conurbação e dispersão urbana. Documentos em Síntese, São Paulo, v.2, n.6, 5-7, jul. 1993. 


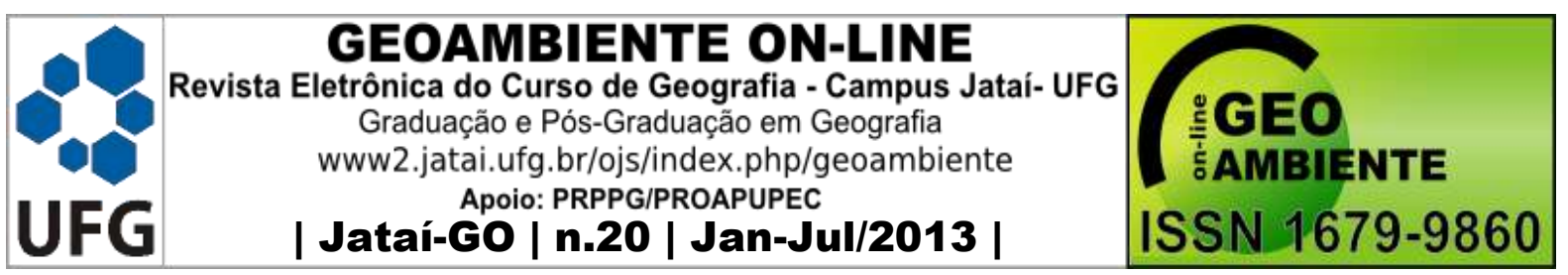

SEADE - Fundação Sistema Estadual de Análise de Dados. São Paulo (Estado). Índices dos Municípios Paulistas. Disponível em: <http://www.seade.gov.br >, São Paulo, 2010. Acesso em: 25 jan. 2012.

SINGER, P. O uso do solo urbano na Economia Capitalista. ㄹ. MARICATTO, E. (Org.). A produção capitalista da casa (e da cidade) no Brasil industrial. 2.ed., Alfa-Ômega, São Paulo, 1982.

SOARES, P. R. R. Cidades médias e aglomerações urbanas: a nova organização do espaço regional no sul do Brasil. In: SPÓSITO, E. S.; SPÓSITO, M. E. B.; SOBARZO, O. (Org.). Cidades médias: produção do espaço. 1 ed., Expressão Popular, São Paulo, 2006.

Novos recortes do território: aglomerações urbanas e desenvolvimento local e regional. In: Jornadas de História Regional Comparada da FEE, 2., Anais...PUCRS, Porto Alegre, 2005. Artigo obtido através do site: http://www.fee.tche.br/sitefee/download/jornadas/2/e4-02.pdf

SOUZA, M. L. de. Mudar a cidade: uma introdução crítica ao planejamento e à gestão urbanos. 4 ed., Bertrand Brasil, Rio de Janeiro, 2006.

SPÓSITO, M. E. B. O chão em pedaços: urbanização, economia e cidades no Estado de São Paulo. Tese (Livre-Docência). Universidade Estadual Paulista, Faculdade de Ciências Tecnologia. Presidente Prudente: [s.n], 508p. 2004.

SPÓSITO, E. S.; SPÓSITO, M. E. B.; SOBARZO, O. (Org.). Cidades médias: produção do espaço, 1 ed., Expressão Popular, São Paulo, 2006.

SPÓSITO, M. E. B. (Org.). Cidades médias: espaço em transição, 1 ed., Expressão Popular, São Paulo, 2007.

Novos conteúdos nas periferias urbanas das cidades médias do Estado de São Paulo, Brasil. Boletín del Instituto de Geografia, Cidade do México, n.54, 114-139, 2009. Artigo obtido através do site: http://www.igeograf.unam.mx/instituto/publicaciones/boletin/bol54/b54art7.pdf____ A A urbanização da sociedade: reflexões para um debate sobre novas formas espaciais, in: CARLOS, A. F. A. et. al. (Org.). O Espaço no Fim do Século: a nova raridade, 2. ed., Contexto, São Paulo, 2001.

TESSARI, L. M. Processo de expansão urbana e conurbação em uma aglomeração urbana não-metropolitana no interior paulista. Dissertação (Mestrado em Organização do Espaço) - 


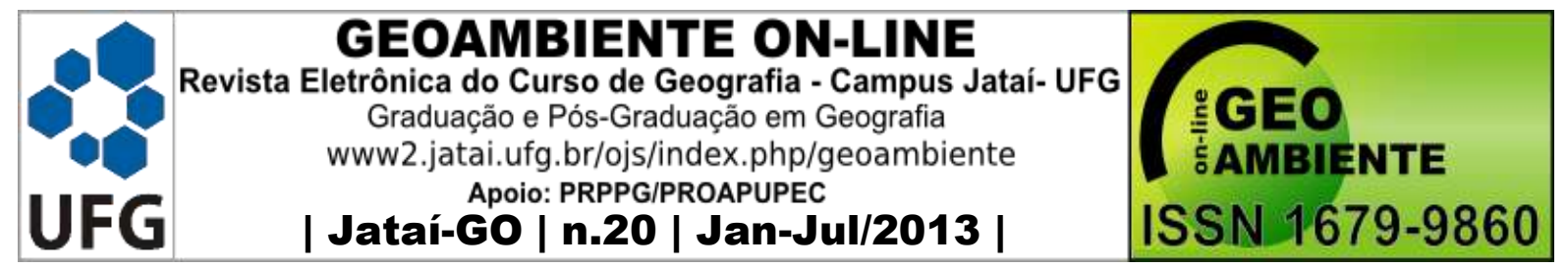

Instituto de Geociências e Ciências Exatas, Universidade Estadual Paulista, Rio Claro - SP. 163p. 2009.

; BRAGA, R. Segregação e periferização urbana em cidades pequenas: o caso de Gavião Peixoto-sp. Geoambiente On-line, v. 10, 214-231, 2008.

VILLAÇA, F. Espaço intra-urbano no Brasil. Studio Nobel, São Paulo. 